\title{
A Study on the Dynamic Strength Deterioration Mechanism of Frozen Red Sandstone at Low Temperatures
}

\author{
Yang Yang ${ }^{1}$, Niannian Zhang ${ }^{2}$ and Jianguo Wang ${ }^{3, * \mathbb{D}}$ \\ 1 School of Civil and Resources Engineering, University of Science and Technology Beijing, \\ Beijing 100083, China; yangyang@ustb.edu.cn \\ 2 Yunnan Superstar Certified Safety Engineer Office Co., Ltd., Kunming 650106, China; znn88916@163.com \\ 3 Faculty of Land Resources Engineering, Kunming University of Science and Technology, \\ Kunming 650093, China \\ * Correspondence: wangjg0831@163.com
}

Citation: Yang, Y.; Zhang, N.; Wang, J. A Study on the Dynamic Strength Deterioration Mechanism of Frozen Red Sandstone at Low Temperatures. Minerals 2021, 11, 1300. https:// doi.org/10.3390/min11121300

Academic Editor: Stephen E. Laubach

Received: 9 October 2021

Accepted: 18 November 2021

Published: 23 November 2021

Publisher's Note: MDPI stays neutral with regard to jurisdictional claims in published maps and institutional affiliations.

Copyright: (c) 2021 by the authors. Licensee MDPI, Basel, Switzerland. This article is an open access article distributed under the terms and conditions of the Creative Commons Attribution (CC BY) license (https:/ / creativecommons.org/licenses/by/ $4.0 /)$.

\begin{abstract}
In this study, the dynamic mechanical properties of red sandstone at low temperatures were studied by performing SHPB dynamic impact tests. According to damage and energy theories, the influences of different low temperatures on the dynamic strength, damage variable, and energy dissipation of red sandstone were analyzed. Combined with a fracture morphology analysis, the deterioration mechanism of the dynamic mechanical strength of red sandstone was deduced at lower negative temperatures. The research results showed that lower negative temperatures $\left(<-30{ }^{\circ} \mathrm{C}\right)$ caused "frostbite" in red sandstone, which resulted in a sharp reduction in the macroscopic, dynamic mechanical strength of rock under high strain. Transient engineering disasters can easily occur under such a dynamic disturbance. According to the fracture morphology analysis, low temperatures generated a large number of cracks at the interface between the components of red sandstone. The plastic deformation ability of the crack tip was poor, and stability loss and expansion under high strain rate were readily achieved, resulting in low-stress brittle failure. However, due to the complex mineral composition of the cementitious materials, they were more susceptible to low temperature. Therefore, under the double action of dynamic load and low temperatures, it was found that damage occurred in the cementitious materials first, and then fracture of the red sandstone as a whole resulted.
\end{abstract}

Keywords: frozen red sandstone; dynamic strength deterioration; damage variable; fracture morphology

\section{Introduction}

The mechanical response of rock at low temperature is significantly different from that at room temperature [1,2]. Especially in the case of lower negative temperature, uniaxial compressive strength, tensile strength, and elastic modulus of rock increase significantly with a decrease in negative temperature [3-5]. In the meantime, the internal friction angle and cohesion also increase [6-10], and the overall static performance of rock is enhanced. However, negative temperatures can also make rocks more brittle, and failure strain is reduced. Meanwhile, rocks also bear huge ice swelling forces brought by water-ice phase transformation, which can lead to sudden engineering disasters occurring more easily in geotechnical engineering in cold areas. In addition, in cold climate regions, rocks are subjected to repeated processes of freeze-thaw weathering and, consequently, the integrity of those rocks gradually deteriorates [11,12]. Therefore, it is key to solve the problem of mineral resource exploitation and geotechnical engineering construction in cold regions to reveal and understand the mechanical properties of rocks, especially the dynamic properties under low negative temperatures.

However, as compared with the numerous studies in the field of rock statics [13-19], dynamic studies are relatively scarce, and most of them have focused on $-20{ }^{\circ} \mathrm{C}$ temperature conditions, which are not low enough to fully reflect the influence of negative temperature changes on rock dynamic characteristics, let alone to explore the dynamic 
disaster mechanism of geotechnical engineering in cold regions. According to the above problem, in the present study, a dynamic impact test of water-saturated frozen red sandstone is carried out by using a split Hopkinson pressure bar (SHPB) experimental system to study the dynamic mechanical properties of low-temperature frozen red sandstone under compression load. The range of test temperatures is from $25^{\circ} \mathrm{C}$ to $-40{ }^{\circ} \mathrm{C}$, which can comprehensively reflect the influence of low temperatures on rock dynamic behaviors. In addition, combined with scanning electron microscopy, the microscopic fracture characteristics of frozen rock are accurately characterized by fracture morphology analysis. On this basis, the effects of low temperatures and water-ice phase transformation on dynamic mechanical strength and deformation characteristics of rock are studied.

\section{Dynamic Impact Test of Frozen Red Sandstone}

\subsection{Specimen Preparation and Corresponding Parameters}

The red sandstones were taken from the Hongqinghe Coal Mine. According to the test standard recommended by the Society of Rock Dynamics, cylindrical specimens with $\phi 74 \times 37 \mathrm{~mm}$ were prepared (see Figure 1), ensuring that the end face and axial direction of the specimens met the requirements of flatness and straightness, respectively (see Figure 2). The prepared red sandstone specimens were saturated or dried and their basic physical parameters were measured (see Table 1), and then the freezing treatment and comparison group tests were conducted.

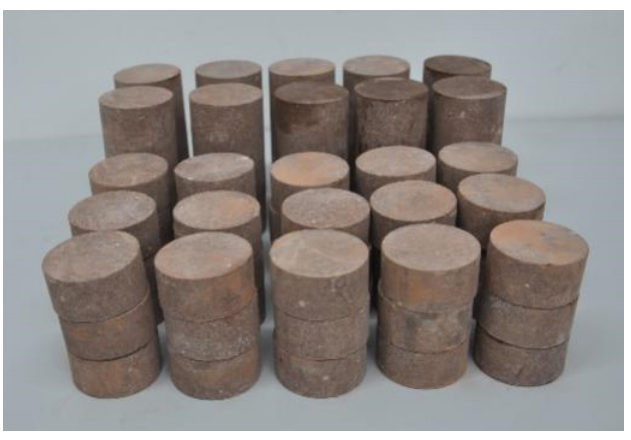

Figure 1. Some of the prepared rock specimens.

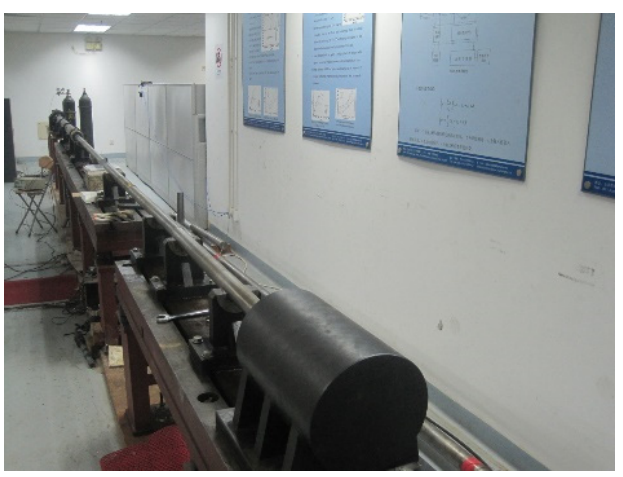

Figure 2. The SHPB experimental system.

Table 1. Basic physical parameters of red sandstone.

\begin{tabular}{cccccc}
\hline \multirow{2}{*}{ Rock Type } & $\begin{array}{c}\text { Velocity of Longitudinal } \\
\text { Wave } \mathbf{~ m} \cdot \mathbf{s}^{-\mathbf{1}}\end{array}$ & $\begin{array}{c}\text { Dry Density } \\
\mathbf{k g} \cdot \mathbf{m}^{-3}\end{array}$ & $\begin{array}{c}\text { Saturated } \\
\text { Density } \mathbf{~ k g} \cdot \mathbf{m}^{-3}\end{array}$ & $\begin{array}{c}\text { Saturation } \\
\text { Rate } \%\end{array}$ \\
\cline { 2 - 3 } $\begin{array}{c}\text { Red } \\
\text { sandstone }\end{array}$ & 2780 & 3651 & 2292 & 2371 & 3.46 \\
\hline
\end{tabular}




\subsection{Experimental Scheme}

The strain rates that correspond to engineering projects, such as mechanical or blasting excavation of frozen vertical shaft, vibration loading of geotechnical engineering in cold areas, impact loading, and seismic loading of liquefied natural gas and LPG reservoir are mostly in the range of 10 1000, which belong to medium and high strain rates, and their dynamic mechanical properties can be tested through a Hopkinson experimental system. Therefore, this study is based on the dynamic impact test, and an SHPB experimental system is used to simulate the dynamic disturbance of cryogenic frozen rock during engineering construction or service.

The preparation of low-temperature frozen rock specimens was accomplished in a high- and low-temperature testing machine. After dropping to the specified temperature, the specimens needed to be stabilized in a low-temperature chamber for at least $24 \mathrm{~h}$ to ensure consistency of the temperatures inside and outside the specimens. For the SHPB dynamic impact test under high strain rate, the gas pressure was set at $0.72 \mathrm{MPa}$. The average strain rate of red sandstone is $101 \mathrm{~s}^{-1}$. According to freezing temperature, the specimens were divided into the following seven groups (at least three specimens in each group): the $25{ }^{\circ} \mathrm{C}$ Group, $-5{ }^{\circ} \mathrm{C}$ Group, $-10{ }^{\circ} \mathrm{C}$ Group, $-15^{\circ} \mathrm{C}$ Group, $-20{ }^{\circ} \mathrm{C}$ Group, $-30{ }^{\circ} \mathrm{C}$ Group, and $-40{ }^{\circ} \mathrm{C}$ Group. During the experiment, the specimens needed to be quickly transferred to the Hopkinson experimental device from the freezing chamber; the transfer time should be less than $30 \mathrm{~s}$. Due to the poor thermal conductivity of rock and the short transfer time, we considered that the overall temperature of the rock specimens were not affected by the external room temperature $\left(25^{\circ} \mathrm{C}\right)$ during the entire experimental process. In addition to the dynamic impact test on saturated rock, a contrast test on a dry specimen group was also conducted to analyze the influence of water and the water-ice phase transformation on the mechanical properties of rock at high strain rates.

\section{Temperature Effect on Mechanical Properties of Red Sandstone under High Strain Rate}

\subsection{Analysis of Dynamic Mechanical Properties}

The dynamic compressive strength and failure strain of water-saturated red sandstone at different temperatures were obtained according to the measured voltage value, and the curves of corresponding characteristic parameters changing with temperature were drawn, as shown in Figures 3 and 4.

The results of the low-temperature rock statics tests show that the uniaxial and triaxial compressive strengths of rock increase with a decrease in temperature at negative temperatures [13-15]. However, under high strain rate, we found that low negative temperatures caused "frostbite" effects in rocks, that is, large numbers of microcracks and intermedium spaces were produced in rocks due to the differences in shrinkage rates and degrees of solid ice, minerals, and other media under low negative temperatures. These secondary defects were prominent in the deterioration of rocks under high strain rate, resulting in a decrease in dynamic compressive strength of the rocks. These results are different from the results obtained from static and quasi-static tests, in which the strength increases as the temperature decreases. As can be seen from Figure 5, the dynamic compressive strength of water-saturated red sandstone decreases from 122 to $86 \mathrm{MPa}$ in the temperature range from $-30{ }^{\circ} \mathrm{C}$ to $-40{ }^{\circ} \mathrm{C}$, the reduction ratio of which is about $41.68 \%$, and the rock dynamic performance is greatly degraded. The dynamic compressive strength of red sandstone at $-10{ }^{\circ} \mathrm{C},-15{ }^{\circ} \mathrm{C},-20{ }^{\circ} \mathrm{C}$, and $-30{ }^{\circ} \mathrm{C}$ increases by $14.87 \%, 16.87 \%, 22.84 \%$, and $23.97 \%$, respectively, as compared with that at $-5^{\circ} \mathrm{C}$. These results indicate that a negative temperature from $-5^{\circ} \mathrm{C}$ to $-30^{\circ} \mathrm{C}$ is not enough to generate a large number of secondary defects on the interfaces of different media. On the contrary, the rock shrinks when it encounters cold, and the contact between various media is closer, thus, the overall bearing capacity of the rock is enhanced. The variations in the failure strain of red sandstone reflect that with a decrease in temperature (from $25^{\circ} \mathrm{C}$ to $-10^{\circ} \mathrm{C}$ ), the brittleness of the rock gradually increases, and it is easy to go from small deformation to failure directly, and therefore the 
failure strain value gradually decreases. However, with a further decrease in temperature, secondary defects caused by the lower negative temperature begin to appear in the rock. These defects further develop and expand under the impact load, resulting in an increase in rock failure strain.

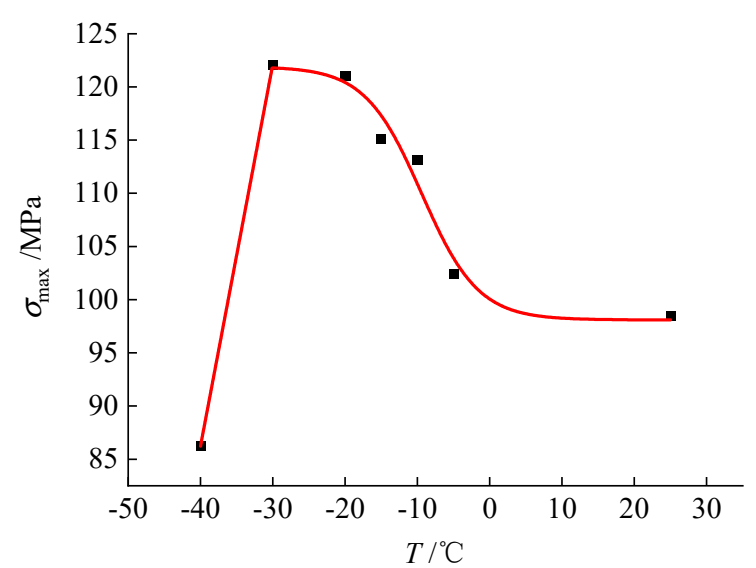

Figure 3. Dynamic compressive strength of water-saturated red sandstone at different temperatures.

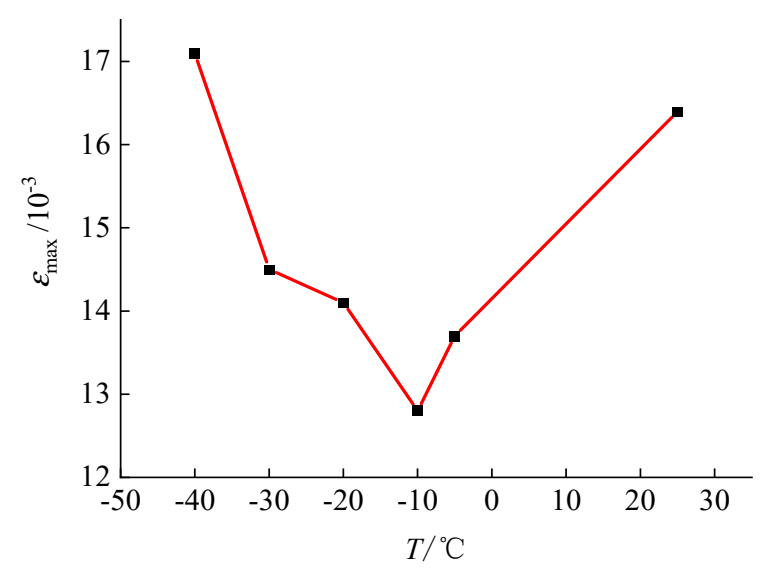

Figure 4. Failure strain change of water-saturated red sandstone at different temperatures.

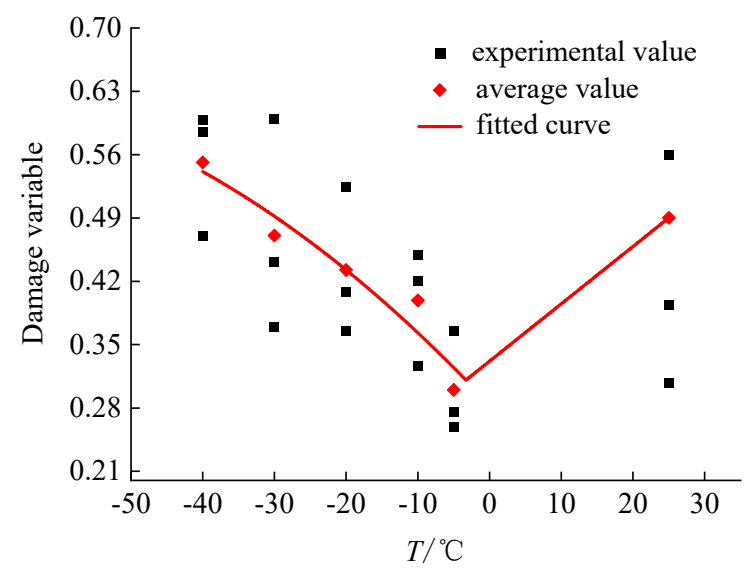

Figure 5. Relationship between damage variable and temperature in the dynamic impact test.

The above analysis of the dynamic mechanical property curve shows that "frostbite" occurs in red sandstone when the temperature drops to $-30^{\circ} \mathrm{C}$, that is, the dynamic mechanical properties of red sandstone deteriorate. The reason is that a large number of microcracks occur in negative-temperature-treated rocks under high strain rate loading. 
These microcracks have little effect on rock strength properties under low strain rate or static or quasi-static test conditions, but their effect can be amplified by the high strain rate, resulting in deterioration of rock mechanical properties and a sharp reduction in dynamic mechanical strength.

\subsection{Influence of Negative Temperature on Damage Variables}

The formula for calculating the total dissipated energy density of rock specimens under impact load is as follows:

$$
w_{\mathrm{d}}=\frac{W_{\mathrm{L}}}{V}
$$

where $w_{\mathrm{d}}$ is the total dissipated energy density, $V$ is the specimen volume, and $W_{\mathrm{L}}$ is the total dissipated energy of rock impact failure.

The area enclosed by the stress-strain curve of rock in the SHPB dynamic impact test is considered to be the total absorption energy density $u$ of rock deformation and failure:

$$
u=\int \sigma \mathrm{d} \varepsilon
$$

In order to study the influences of different temperatures on rock dynamic damage, the damage variable $d$ represented by energy concept is introduced $[20,21]$ :

$$
d=\frac{w_{\mathrm{d}}}{u}
$$

where $w_{\mathrm{d}}$ and $u$ represent the total dissipated energy density and total absorbed energy density of rock deformation and failure under impact load, respectively.

According to Equations (1)-(3), the damage variables of red sandstone specimens under impact load are calculated, as shown in Table 2, along with corresponding temperature parameters.

According to general damage rules, it is considered that $d=1.0$ indicates material destruction, but in many cases, when the damage variable value is far less than 1.0, the material may also be destroyed, such as rock material under dynamic loading at negative temperatures. In this study, energy dissipation is used to define the damage variable, and the larger the damage variable value is, the higher the damage and breakage degree of the corresponding rock specimen is. It can be observed from the damage variables in Table 2 that there are significant differences in damage and breakage degrees of red sandstone under the same impact load, which is caused by temperature change, or more specifically, the different negative temperatures encountered by the rock in the saturated state. Although the damage variables in Table 2 represent the damage and failure of rock under impact load, their change trends at different temperatures can still reflect the influence of negative temperature change on rock damage and failure. Figure 5 shows the variation of damage variable and temperature under dynamic impact of red sandstone. It can be seen from the figure that the value of the damage variable $d$ is the minimum at $-5{ }^{\circ} \mathrm{C}$, and the degree of rock breakage is low at $-5^{\circ} \mathrm{C}$ (Figure 6a). When the temperature drops from $25^{\circ} \mathrm{C}$ to $-5^{\circ} \mathrm{C}$, the value of the damage variable decreases sharply, the dissipated energy decreases, and the failure mode of rock changes from severe fracture to bulk splitting. In the temperature range from $-5{ }^{\circ} \mathrm{C}$ to $-40{ }^{\circ} \mathrm{C}$, the damage variable increases gradually as the temperature decreases, the dissipated energy increases gradually, and the degree of breakage gradually intensifies, as shown in Figure 6a-e. As compared with $25^{\circ} \mathrm{C}$, the damage variable of $-30{ }^{\circ} \mathrm{C}$ and $-40{ }^{\circ} \mathrm{C}$ increases by $11.9 \%$ and $30.9 \%$, respectively. The dissipated energy at $-30{ }^{\circ} \mathrm{C}$ and $-40{ }^{\circ} \mathrm{C}$ is also higher than that at $25^{\circ} \mathrm{C}$; correspondingly, the degree of rock breakage is more serious. In the temperature range from $-5^{\circ} \mathrm{C}$ to $-30{ }^{\circ} \mathrm{C}$, the damage variable value $d$ of red sandstone is smaller than that at $25^{\circ} \mathrm{C}$. 
Table 2. The measured damage variables at different temperatures in the dynamic impact test.

\begin{tabular}{|c|c|c|c|c|c|}
\hline \multirow[b]{2}{*}{ Serial Number } & \multirow[b]{2}{*}{$T^{\circ} \mathrm{C}$} & \multirow[b]{2}{*}{$U \mathrm{~J} \cdot \mathbf{m}^{-3}$} & \multirow[b]{2}{*}{$w_{\mathrm{d}} \mathrm{J} \cdot \mathrm{m}^{-3}$} & \multicolumn{2}{|c|}{$d$} \\
\hline & & & & $\begin{array}{l}\text { Experimental } \\
\text { Value }\end{array}$ & Average Value \\
\hline 1 & \multirow{3}{*}{25} & $2,026,020$ & $798,014.6$ & 0.39 & \multirow{3}{*}{0.42} \\
\hline 2 & & $1,824,890$ & $1,022,309.0$ & 0.56 & \\
\hline 3 & & $2,170,870$ & $669,018.2$ & 0.31 & \\
\hline 4 & \multirow{3}{*}{-5} & $2,308,220$ & $635,319.7$ & 0.28 & \multirow{3}{*}{0.30} \\
\hline 5 & & $2,309,290$ & $599,024.3$ & 0.26 & \\
\hline 6 & & $2,036,210$ & $744,266.1$ & 0.37 & \\
\hline 7 & \multirow{3}{*}{-10} & $1,843,130$ & $774,945.0$ & 0.42 & \multirow{3}{*}{0.40} \\
\hline 8 & & $1,829,330$ & $597,333.3$ & 0.33 & \\
\hline 9 & & $1,554,370$ & $698,912.0$ & 0.45 & \\
\hline 10 & \multirow{3}{*}{-20} & $1,803,090$ & $945,189.0$ & 0.52 & \multirow{3}{*}{0.43} \\
\hline 11 & & $2,121,560$ & $775,307.4$ & 0.37 & \\
\hline 12 & & $2,225,180$ & $907,565.0$ & 0.41 & \\
\hline 13 & \multirow{3}{*}{-30} & $2,046,070$ & $904,847.4$ & 0.44 & \multirow{3}{*}{0.47} \\
\hline 14 & & $2,196,160$ & $810,938.4$ & 0.37 & \\
\hline 15 & & $1,944,590$ & $1,167,188.0$ & 0.60 & \\
\hline 16 & \multirow{3}{*}{-40} & $2,000,980$ & $941,746.6$ & 0.47 & \multirow{3}{*}{0.55} \\
\hline 17 & & $1,754,530$ & $1,049,546.0$ & 0.60 & \\
\hline 18 & & $1,658,340$ & $970,915.8$ & 0.59 & \\
\hline
\end{tabular}

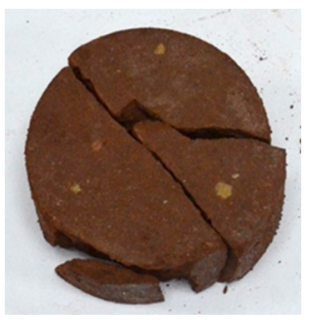

(a)

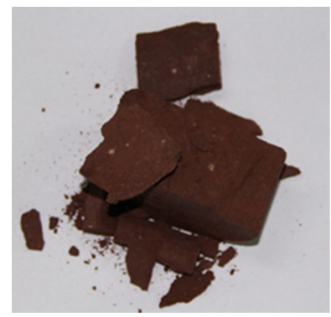

(b)

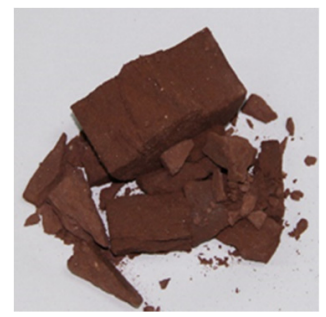

(c)

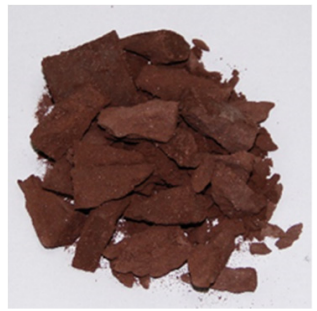

(d)

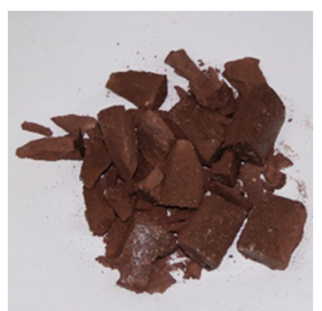

(e)

Figure 6. Failure modes of red sandstone at different negative temperatures. $\left.\left.(\mathbf{a})-5{ }^{\circ} \mathrm{C}, \mathbf{b}\right)-10{ }^{\circ} \mathrm{C},(\mathbf{c})-20{ }^{\circ} \mathrm{C}, \mathbf{d}\right)-30{ }^{\circ} \mathrm{C}$, (e) $-40^{\circ} \mathrm{C}$.

According to Section 3.1, the change from normal temperature to negative temperatures within the range from $25^{\circ} \mathrm{C}$ to $-30^{\circ} \mathrm{C}$ improves the impact resistance of watersaturated frozen red sandstone, and thus the dynamic compressive strength is significantly improved. However, with a decrease in negative temperature (from -5 to $-30^{\circ} \mathrm{C}$ ), red sandstone tends to be brittle. In detail, under the same impact load, the failure strain value becomes smaller, the dissipated energy increases, and the failure degree of rock gradually intensifies. Under temperatures lower than $-30^{\circ} \mathrm{C}$, the dissipated energy and damage variables continue to increase, but the dynamic compressive strength of rock specimens decreases sharply, and the impact failure resistance decreases significantly, inducing deterioration of the dynamic mechanical properties at lower negative temperatures.

The values of damage variable of water-saturated red sandstone under dynamic impact do not change continuously in the temperature range from 25 to $-5^{\circ} \mathrm{C}$, but their variation in the range from $-5^{\circ} \mathrm{C}$ to $-40{ }^{\circ} \mathrm{C}$ has regularity, thus, the values of damage variable and temperature in this negative temperature range can be fitted as the following Equation (4):

$$
\begin{gathered}
d=-5.04739 \mathrm{e}^{-5} \mathrm{~T}^{2}-0.00846 \mathrm{~T}+0.28345 \\
\left(R^{2}=0.95738\right), T \in[-40,-5]
\end{gathered}
$$




\subsection{Macroscopic Failure Pattern of Red Sandstone at Negative Temperatures}

As shown in Figure 6, under the same impact pressure loading, the water-saturated red sandstone under different negative temperature conditions shows different failure modes. Firstly, at $-5^{\circ} \mathrm{C}$, the red sandstone fractures into several large pieces under the action of stress waves, and the failure surfaces are mostly inclined at $90^{\circ}$ angle with obvious tensile traces. From $-10{ }^{\circ} \mathrm{C}$ to $-20^{\circ} \mathrm{C}$, the degree of rock fragmentation intensifies, and a large number of fragments and a small number of conical structures appear in addition to the existence of tensile splitting bodies. From $-30{ }^{\circ} \mathrm{C}$ to $-40{ }^{\circ} \mathrm{C}$, the rock is further broken, and the broken body is mainly a small cone body with strong shear action. In conclusion, the breakage degree of red sandstone at high strain rate gradually intensifies with a decrease in negative temperature, and the failure mode also changes under different temperatures, from the initial tension failure to the shear failure.

According to the analyses of Sections 3.1 and 3.2, it can be inferred that the intervention of initial negative temperature $\left(-5^{\circ} \mathrm{C}\right)$ leads to the transformation of pore water in sandstone into ice. Ice can effectively fill and bond the pores and microfissures in sandstone, and enhance the adhesion between mineral particles. Therefore, the rock integrity is enhanced, the effective bearing area is increased, and the dynamic strength is also improved. At this point, the sandstone is more prone to tensile failure along the loading direction under impact. When the negative temperature further decreases (from -10 to $-30{ }^{\circ} \mathrm{C}$ ), the water-saturated frozen red sandstone shows a shrinking trend as a whole, and the interlocking between mineral particles and solid ice is closer. The dynamic mechanical strength of rock is greatly improved. In this condition, negative temperature is equivalent to applying precompression stress to the rock specimen, thus, the rock specimen has a certain ability to resist radial expansion deformation. However, it is still sensitive to radial shrinkage deformation (and becomes more sensitive with a decrease in negative temperature), and therefore the number of fragments under the action of reverse tensile stress wave continuously increases. There are large numbers of microcracks and weak structures produced in the rock, and these weak structures converge into a large number of shear cracks at the mesoscopic level, causing the rock to show shear failure and disintegration and resulting in a large number of conical fracture fragments [15-18]. Table 3 shows the macroscopic failure characteristics of red sandstone at different temperatures.

Table 3. Macroscopic failure characteristics of red sandstone at different temperatures.

\begin{tabular}{|c|c|c|c|}
\hline $\mathrm{T}$ & $-5{ }^{\circ} \mathrm{C}$ & $-10 \sim-30{ }^{\circ} \mathrm{C}$ & $-40^{\circ} \mathrm{C}$ \\
\hline $\begin{array}{l}\text { Characteristics of } \\
\text { macroscopic failure }\end{array}$ & $\begin{array}{l}\text { Damage mode is given priority with } \\
\text { the tension damage. The shape of } \\
\text { broken body is mainly the columnar } \\
\text { splitting structure. }\end{array}$ & $\begin{array}{l}\text { The failure mode changes from tensile } \\
\text { failure to shear failure. The number of } \\
\text { columnar splitting structures decrease, } \\
\text { while the number of lamellar } \\
\text { spallation structures increase. }\end{array}$ & $\begin{array}{c}\text { Shear failure is the main failure mode, } \\
\text { and the shape of the broken body is } \\
\text { mainly the lamellar and conical } \\
\text { structure. }\end{array}$ \\
\hline Change law of & \multicolumn{2}{|c|}{ Gradually Increasing } & Dramatically reducing \\
\hline Cause analysis & $\begin{array}{l}\text { The water-ice phase transformation } \\
\text { occurs, the bond between mineral } \\
\text { particles increases, the rock integrity is } \\
\text { enhanced, and the dynamic strength is } \\
\text { improved. Sandstone with enhanced } \\
\text { brittleness and integrity is more prone } \\
\text { to tensile failure along the loading } \\
\text { direction under impact load. }\end{array}$ & $\begin{array}{l}\text { With a decrease in negative } \\
\text { temperature, the red sandstone } \\
\text { shrinks as a whole, and the interlacing } \\
\text { between mineral particles and solid } \\
\text { ice becomes closer, and the dynamic } \\
\text { mechanical strength increases } \\
\text { significantly. The resistance of rock to } \\
\text { radial contraction is further reduced, } \\
\text { and the rock fracture is lamellar } \\
\text { structure under the action of reverse } \\
\text { tensile wave. }\end{array}$ & $\begin{array}{l}\text { The shrinkage rate and amplitude of } \\
\text { each component material in sandstone } \\
\text { are quite different when it is cooled. } \\
\text { A large number of cracks are formed } \\
\text { at the contact of the components, } \\
\text { and the plastic deformation ability at } \\
\text { the crack tip is poor. Low stress brittle } \\
\text { failure occurs easily under negative } \\
\text { temperature and high strain rate } \\
\text { loading, and the strength drops } \\
\text { sharply. }\end{array}$ \\
\hline
\end{tabular}




\section{Analysis of Mesoscopic Fracture Morphology}

The fracture morphology of water-saturated red sandstone at different temperatures is observed in order to explore the deterioration mechanism of dynamic mechanical properties of rock at lower negative temperatures.

Red sandstone is a multiphase body composed of mineral particles and cementation, and there are a lot of medium voids inside. Under the action of negative temperature, the rock shrinks, some voids close, and the connection and occlusion between the components become closer. As compared with a normal temperature fracture, the roughness of the microscopic fracture is lower, the mineral particles can be seen but the three-dimensional sense is lower, and the integration with the surrounding cements and other matrix components is significant (see Figure $7 \mathrm{a}-\mathrm{c}, \times 150$ represents a magnification of 150 times). The rock is more compact and has higher strength as a whole. However, at lower negative temperatures, due to the great difference in shrinkage rate and amplitude among mineral particles, ice media, cementation components, and other media, the separation phenomenon between components is very apparent, and the three-dimensional sense of fracture morphology is enhanced. The mineral particles are prominent, and the cementation and matrix components are broken in disorder (see Figure $7 \mathrm{~d}-\mathrm{f}$ ). At this time, a large number of pores, voids, and microcracks are generated at the interfaces of the media (see Figure 8). Under dynamic load, these defective structures and microcracks are easy to develop rapidly and even expand unstably, resulting in component separation, particle stripping, and other fracture phenomena under shear action.

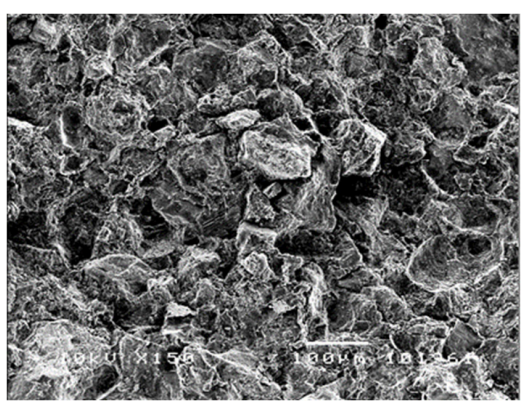

(a)

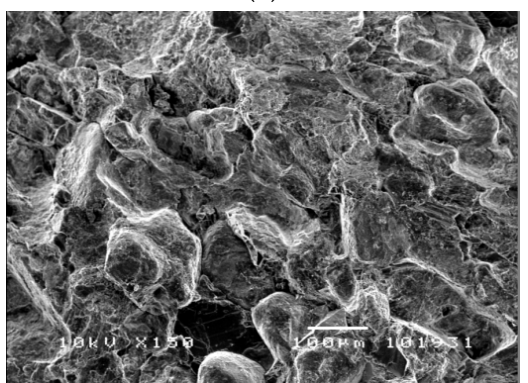

(c)

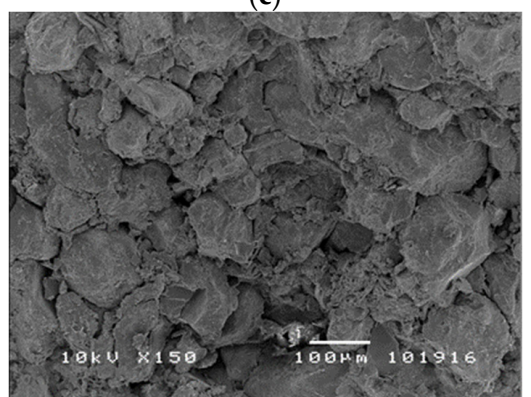

(e)

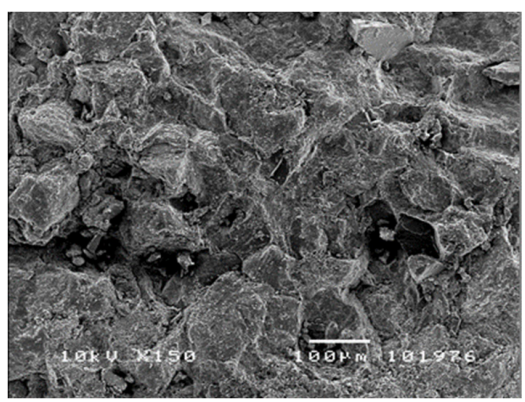

(b)

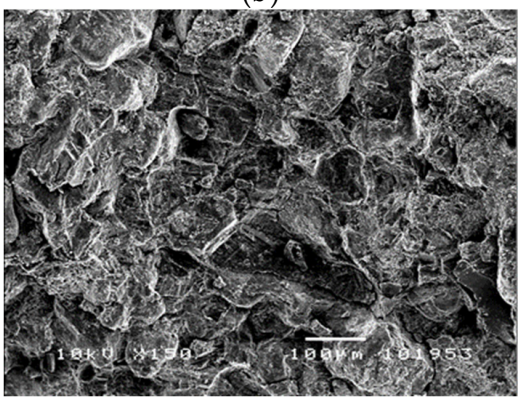

(d)

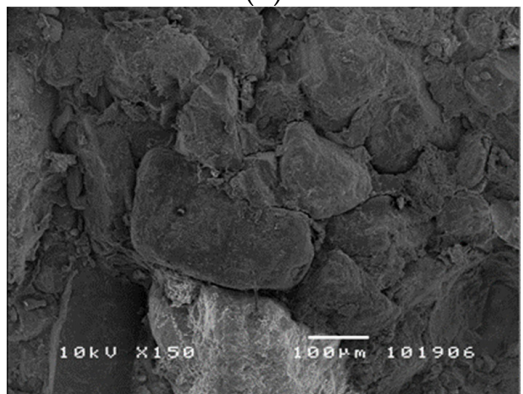

(f)

Figure 7. Fracture morphology of red sandstone at different temperatures. (a) $25^{\circ} \mathrm{C}$ red sandstone, $\times 150,(\mathbf{b})-5{ }^{\circ} \mathrm{C}$ red sandstone, $\times 150,(\mathrm{c})-10{ }^{\circ} \mathrm{C}$ red sandstone, $\times 150,(\mathrm{~d})-20{ }^{\circ} \mathrm{C}$ red sandstone, $\times 150,(\mathbf{e})-30{ }^{\circ} \mathrm{C}$ red sandstone, $\times 150,(\mathbf{f})-40{ }^{\circ} \mathrm{C}$ red sandstone, $\times 150$. 


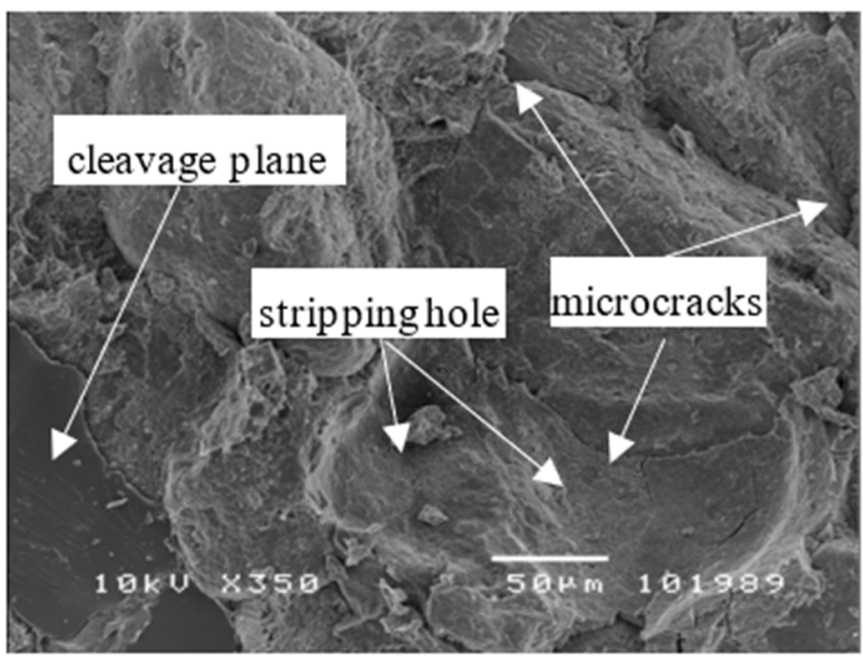

(a)

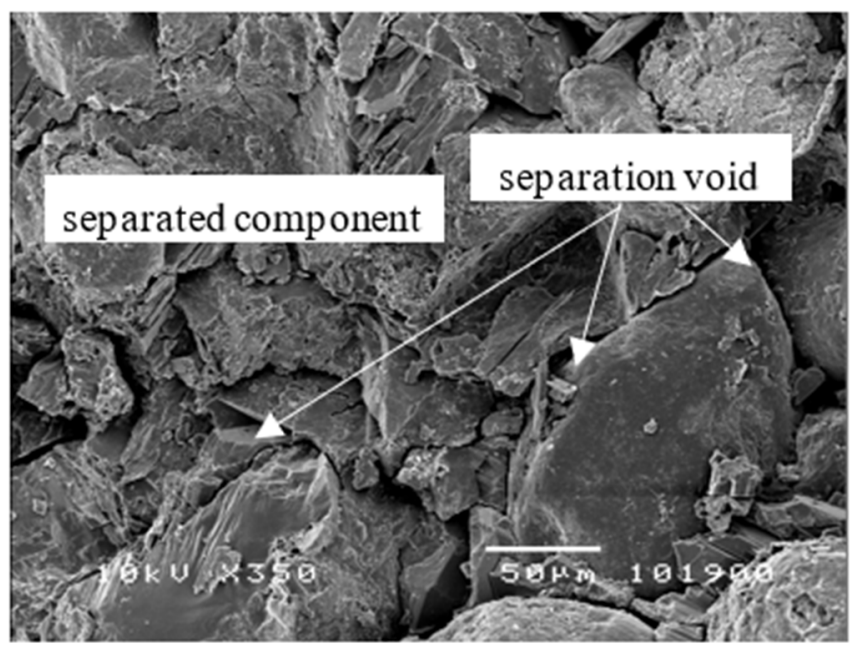

(b)

Figure 8. Local microscopic fracture morphology. (a) $-40^{\circ} \mathrm{C}$ red sandstone, $\times 350,(\mathbf{b})-30{ }^{\circ} \mathrm{C}$ red sandstone, $\times 350$.

According to the observation of fracture morphology in Figure $8(\times 350$ represents a magnification of 350 times), it can be found that the fracture modes of saturated frozen red sandstone are mainly cement fracture and brittle fracture. Among them, due to the complex mineral composition of the cementitious materials, they were more susceptible to low temperature. Therefore, under the double action of dynamic load and low temperatures, it was found that the damage occurred at the cementitious materials first, and then caused the fracture of the red sandstone as a whole.

\section{Discussion}

\subsection{Influence of Water-Ice Phase Transformation on Dynamic Strength of Red Sandstone}

According to the comparison of Figures 3 and 9, it is found that as the temperature drops to negative values, the dynamic compressive strength of the two red sandstones in the comparison group increases under cold contraction, but there is a large difference between them. The dynamic compressive strength of the dry red sandstone increases by $14 \%$, while that of the water-saturated red sandstone only increases by $4 \%$, with a difference of $10 \%$. Therefore, it can be inferred that water-ice phase transformation has a certain degree of deterioration effect in the strength of saturated rock under high strain rate conditions. 


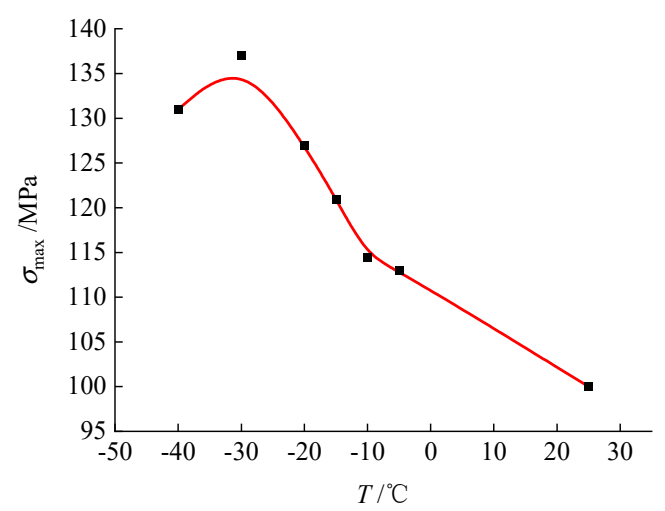

Figure 9. Dynamic compressive strength of dry red sandstone at different temperatures.

The phenomenon, in which pore water transfers from liquid to solid, increases the water volume by $9 \%$, which can produce ice expansion force within the rock. According to related studies $[1,2]$, under the condition of no drainage and consolidation, the ice expansion force in water-saturated rock is up to $200 \mathrm{MPa}$. These ice expansion forces can produce microcracks in the rock, and can also expand the original cracks. Referring to the above research conclusions and combined with the present test, it can be determined that the ice expansion force in water-saturated red sandstone leads to a large number of microcracks in the rock. These microcracks can reduce the dynamic mechanical strength of water-saturated red sandstone as compared with dry red sandstone. The deterioration of strength can be obviously detected only by comparison, because the macroscopic strength of the overall contraction and compaction of the two rocks increases under the condition of negative temperature.

\subsection{Fracture Mode of Frozen Red Sandstone}

In the field of mesofracture, the order of energy dissipation of fracture modes under the same conditions is as follows: cement fracture $\leq$ intergranular fracture $\leq$ transgranular fracture $\leq$ quasi cleavage fracture [22,23]. According to the analysis of Sections 3 and 4 , it is found that dynamic strength and dissipated energy correspond to the fragmentation and fracture mode, as shown in Table 4.

Table 4. Fracture model vs. dissipated energy.

\begin{tabular}{cccc}
\hline $\boldsymbol{T}^{\circ} \mathbf{C}$ & Fracture Mode & Dynamic Strength MPa & Dissipated Energy $\boldsymbol{W}_{\mathbf{L}} \mathbf{J}$ \\
\hline 25 & $\begin{array}{c}\text { Cement fracture, } \\
\text { intergranular fracture } \\
\text { Cement fracture }\end{array}$ & 98.51 & 147.63 \\
-5 & Cement fracture & 102.47 & 109.10 \\
-10 & $\begin{array}{c}\text { Cement fracture } \\
-20\end{array}$ & 121.01 & 131.63 \\
-30 & $\begin{array}{c}\text { Cement fracture, } \\
\text { intergranular fracture } \\
\text { Cement fracture, } \\
-40\end{array}$ & 122.12 & 145.05 \\
& transgranular fracture & 86.23 & 158.78 \\
\hline
\end{tabular}

As shown in Table 4, the fracture mode of red sandstone at various temperatures under the same impact load has significant differences, which further induces differences in the failure mode and fragmentation of rock, and the dissipated energy required for rock fragmentation, thus, affecting the macroscopic mechanical strength of rock.

According to the change of fracture mode and fracture morphology, it can be inferred that a low negative temperature (in this series of tests, it means the temperature after dropping to $-30^{\circ} \mathrm{C}$ ) will cause "frostbite" in red sandstone under high strain rate, that is, the dynamic compressive strength and bearing capacity of red sandstone will decrease, which is called "frostbite effect" under high strain rate. Many researchers [3-8] have 
conducted numerous negative temperature loading tests on rocks under static or quasistatic conditions. However, the results have shown that even when the temperature dropped to $-160^{\circ} \mathrm{C}$, there was no "frostbite" phenomenon of strength decline that occurred, which indicated that the occurrence of frostbite was related to the loading method, and the frostbite effect occurred only in the combination of low negative temperature and high strain rate loading.

To some extent, the water-ice phase transformation will deteriorate the dynamic strength of water-saturated red sandstone, which does not occur in the static load test, indicating that the rock bearing capacity under high strain rate is more sensitive to microcracks, microvoids, and other defect structures. However, in static or quasi-static cases, due to a long loading time and low strain rate, the rock has a relatively long compaction stage (or crack closure stage), and it is not so sensitive to the emergence of microdefect structure, which is reflected in the macroscopic view that its strength does not decrease significantly. This insensitivity to microdefect structure becomes more prominent when the temperature is lower than $-30^{\circ} \mathrm{C}$. Under high strain rate loading, the dynamic compressive strength of red sandstone decreases sharply after $-30^{\circ} \mathrm{C}$, while its static strength continues to increase, and even increases faster at lower negative temperatures $[3,4]$. In the present experiment, it is observed that the dynamic mechanical strength of red sandstone decreases after $-30{ }^{\circ} \mathrm{C}$, because the overall property of red sandstone tends to be brittle after this temperature, and different materials (such as mineral particles, cemented materials, and solid ice) in the rock have great differences in shrinkage rate and shrinkage amplitude when they are cooled. Therefore, a large number of secondary defects such as microvores and microcracks are produced at the contact interface of the components. These secondary defects have poor plastic deformation ability under the action of negative temperature. Under the loading of high strain rate, low stress brittle failure often occurs directly without any deformation, thus, leading to a sharp decline in the strength and bearing capacity of red sandstone. Under static or quasi-static loading, negative temperature will also generate secondary defects in rocks [13-15]. However, because under negative temperature rocks have enough time for defects to close during a longer loading time, even if there is local microscopic fracture, a lower negative temperature can make the rock shrink and tightly restrain its development. Therefore, it is impossible for high strain rate instantaneous loading to occur (under high strain rate loading in low temperature brittle media, cracks are usually quite unstable and difficult to suppress).

The strength deterioration of red sandstone after $-30{ }^{\circ} \mathrm{C}$ is because different materials (such as mineral particles, cemented materials, and solid ice) in the rock have great differences in shrinkage rate and amplitude when they are cooled, and a large number of cracks are generated at the interface between the constituent materials. As compared with mineral particles, cement is more susceptible to negative temperatures due to its complex composition. Therefore, under the coupling action of dynamic load and negative temperatures, cement is usually destroyed first, which leads to the overall fracture of red sandstone.

\section{Conclusions}

In this study, a dynamic impact experiment on low-temperature frozen red sandstone was carried out to study the temperature effect on the dynamic mechanical properties of red sandstone under high strain rates. On the basis of existing damage and energy theories, the effects of different low temperatures on the strength, damage variables, and energy dissipation of red sandstone were analyzed. Combined with the fracture morphology analysis, the deterioration mechanism of the dynamic mechanical strength of red sandstone at lower negative temperatures was deduced.

(1) A change in negative temperature significantly affects the dynamic mechanical properties of red sandstone, which is equivalent to applying precompression stress to red sandstone. Although the rock tends to be brittle as a whole, its ability to resist tensile 
stress is enhanced. Therefore, within the range from $25^{\circ} \mathrm{C}$ to $-30{ }^{\circ} \mathrm{C}$, its dynamic compressive strength increases gradually with a decrease in temperature.

(2) Lower negative temperatures lead to "frostbite" and deterioration of dynamic mechanical properties of red sandstone under high strain rate loading. The test results show that the dynamic compressive strength of red sandstone decreases sharply after $-30{ }^{\circ} \mathrm{C}$, which is different from the results obtained in static or quasi-static tests at $-30{ }^{\circ} \mathrm{C}$.

(3) At high strain rates, the fracture degree of red sandstone gradually intensifies with a decrease in negative temperature (from -5 to $-40{ }^{\circ} \mathrm{C}$ ), and the failure mode of the stone gradually transitions from the initial negative temperature tension failure to the slip shear failure at a lower negative temperature, which is consistent with the transformation of the internal structural fracture mode at the mesoscopic level.

Author Contributions: Data curation, Y.Y., N.Z. and J.W.; Validation, N.Z.; Writing-original draft, Y.Y., N.Z. and J.W.; Writing-review and editing, Y.Y. and J.W. All authors have read and agreed to the published version of the manuscript.

Funding: This research was funded by the Key project of the National Natural Science Foundation of China, grant number 51934001.

Data Availability Statement: The experimental data used to support the findings of this study are included within the article.

Acknowledgments: The authors thank the China University of Mining and Technology (Beijing), for providing instruments to conduct the research.

Conflicts of Interest: The authors declare that they have no conflict of interest. The funders had no role in the design of the study; in the collection, analyses, or interpretation of data; in the writing of the manuscript, and in the decision to publish the results.

\section{References}

1. Liu, Q.S.; Huang, S.B.; Kang, Y.S.; Cui, X. Advance and review on freezing-thawing damage of fractured rock. Chin. J. Rock Mech. Eng. 2015, 34, 452-471.

2. Chen, W.Z.; Tan, X.J.; Yu, H.D.; Yuan, K.; Li, S. Advance and review on thermo-hydro-mechanical characteristics of rock mass under condition of low temperature and freeze-thaw cycles. Chin. J. Rock Mech. Eng. 2011, 30, 1318-1336.

3. Aoki, K.; Hibiya, K.; Yoshida, T. Storage of refrigerated liquefied gases in rock caverns: Characteristics of rock under very low temperatures. Tunnell. Undergr. Space Technol. 1990, 5, 319-325. [CrossRef]

4. Yamabe, T.; Neaupane, K.M. Determination of some thermo-mechanical properties of Sirahama sandstone under subzero temperature condition. Int. J. Rock Mech. Min. Sci. 2001, 38, 1029-1034. [CrossRef]

5. Dwivedi, R.D.; Soni, A.K.; Goel, R.K.; Dube, A.K. Fracture toughness of rocks under sub-zero temperature conditions. Int. J. Rock Mech. Min. Sci. 2000, 37, 1267-1275. [CrossRef]

6. Tang, M.M.; Wang, Z.Y.; Sun, Y.L.; Ba, J. Experimental study of mechanical properties of granite under low temperature. Chin. J. Rock Mech. Eng. 2010, 29, 787-794.

7. Xi, J.M.; Yang, G.S.; Pang, L.; Lv, X.-T.; Liu, F.-L. Experimental study on basic mechanical behaviors of sandy mudstone under low freezing temperature. J. China Coal Soc. 2014, 39, 1262-1268.

8. Xu, G.M.; Liu, Q.S.; Peng, W.W.; Chang, X.X. Experimental study on basic mechanical behaviors of rocks under low temperatures. Chin. J. Rock Mech. Eng. 2006, 25, 2502-2508.

9. Yang, G.S.; Lv, X.T. Experimental study on the sandy mudstone mechanical properties of shaft sidewalls under the frozen conditions. J. Min. Saf. Eng. 2012, 29, 492-496.

10. Yang, G.S.; Xi, J.M.; Li, H.J.; Cheng, L.; Lv, X. Experimental study on the mechanical properties of soft rock of coal mine shaft sidewalls under the frozen conditions. Chin. J. Undergr. Space Eng. 2012, 8, 690-697.

11. Lei, W.; Zhi, J.W.; Abbas, T.; Quansheng, L.; Huai, L. Deterioration of dynamic mechanical properties of granite due to freeze-thaw weathering: Considering the effects of moisture conditions. Cold Reg. Sci. Technol. 2020, 176, 103092.

12. Ke, B.; Zhou, K.; Xu, C.; Hongwei, D.; Li, J.; Bin, F. Dynamic mechanical property deterioration model of sandstone caused by freeze-thaw weathering. Rock Mech. Rock Eng. 2018, 51, 2791-2804. [CrossRef]

13. Shan, R.L.; Yang, H.; Zhang, J.X.; Guo, Z.; Dinghong, Z. Mechanical properties of saturated red sandstone of Meilinmiao mine under loading and unloading at negative temperatures. J. Min. Saf. Eng. 2016, 33, 924-931.

14. Shan, R.L.; Yang, H.; Guo, Z.M.; Liu, X.; Song, L. Experimental study of strength characters of saturated red sandstone on negative temperature under triaxial compression. Chin. J. Rock Mech. Eng. 2014, 33, 3657-3664. 
15. Shan, R.L.; Zhang, L.; Yang, H.; Zhang, j.X.; Guo, Z.M. Experimental study of freeze-thaw properties of saturated red sandstone. J. China Univ. Min. Technol. 2016, 45, 923-929.

16. Li, H.J. Experimental Study on Rock Mechanical Properties under Freezing Conditions. Ph.D. Thesis, Xi'an University of Science and Technology, Xi'an, China, 2009.

17. Cheng, L. Experimental Study on Rock Mechanical Properties under Freezing Conditions and Application in Project. Ph.D. Thesis, Xi'an University of Science and Technology, Xi'an, China, 2009.

18. Xi, J.M.; Yang, G.S.; Dong, X.H. Effect of freezing temperature on mechanical properties of sandy mudstone. J. Chang'an Univ. (Nat. Sci. Ed.) 2014, 34, 92-97.

19. Li, Y.P.; Wang, Z.Y. Uniaxial compressive mechanical properties of rock at low temperature. J. Univ. Sci. Technol. Beijing 2011, 33, 671-675.

20. Xu, J.Y.; Fan, J.S.; Lü X, C. Dynamic Mechanical Properties of Rock with the Confining Pressure; Northwestern Polytechnical University Press: Xi'an, China, 2012.

21. Xie, H.P.; Gao, F.; Zhou, H.W.; Zuo, J.P. Fractal fracture and fragmentation in rocks. J. Disasaster Prev. Mitig. Eng. 2003, $23,1-9$.

22. Qian, Y. Experimental Study on Blasting Fragment-Size of Joints Rock Mass based on Fractal Theory. Ph.D. Thesis, Wuhan University of Technology, Wuhan, China, 2005.

23. Wen, M.; Xu, J.Y.; Wang, H.Y.; Fang, X.Y.; Zheng, G.H. Fractography analysis of sandstone failure under low temperature-dynamic loading coupling effects. Chin. J. Rock Mech. Eng. 2017, 36, 3822-3830. 